\title{
Individual, social and environmental determinants of smokeless tobacco and betel quid use amongst adolescents of Karachi: a school-based cross-sectional survey
}

Azmina Hussain ${ }^{1 *}$, Sidra Zaheer $^{2}$ and Kashif Shafique ${ }^{2,3}$

\begin{abstract}
Background: With 600 million people using betel quid (BQ) globally, and smokeless tobacco (SLT) use being more wide-spread; the duo is an uphill public health concern in South Asian countries. SLT and/or BQ use increases the risk for morbidity and mortality from oral cancer. Because SLT and/or BQ use is initiated during adolescence, it renders this group more vulnerable; and particular attention is needed to curb SLT and/or BQ use to reduce related disease burden. We aimed to observe the differential individual, social and environmental features amongst SLT and/or BQ users to determine the key influencers of its use in adolescents.

Methods: This study was a cross-sectional survey of 2140 adolescents from secondary schools of Karachi, Pakistan. The main outcome measure was SLT and/or BQ use based on their consumption in the past 30 days. Univariate and multivariate regression binary logistic analyses were employed while reporting results in both crude form and adjusted odds ratio (after adjusting for all remaining individual, social and environmental level variables) with $95 \%$ confidence level. A $p$-value of $<.05$ was considered significant for all analyses.

Results: The overall prevalence of SLT and/or BQ use was $42.6 \%(n=912)$ of the total sample. The SLT and/or BQ consumer group had more males than females. A significant proportion of user $(n=558,61.2 \%)$ was found in co-education schools. Students whose peers $(\mathrm{OR}=6.79,95 \% \mathrm{Cl} 4.67-9.87, p$-value $<0.001)$ and/or either of the parents $(\mathrm{OR}=2.16,95 \% \mathrm{Cl} 1.73-2.65, p$-value $<0.001)$ used $\mathrm{SLT}$ and/or $\mathrm{BQ}$, alongside, adolescents who had not attended knowledge based sessions in schools regarding harmful effects of SLT and/or BQ were more likely to consume it. It's availability with outside school hawkers increased the odds of its use by 6 times, as indicated by both univariate and multivariate models after adjusting for the remaining variables.

Conclusion: In conclusion, students studying in co-education, parents and peers use, lack of knowledge based sessions on harmful health effects of SLT and/or BQ, and easy availability of the product from hawkers outside school all contribute towards enhanced risk of SLT and/or BQ use in adolescents.
\end{abstract}

Keywords: Smokeless tobacco, Betel quid, Adolescents, Social and environmental determinants

\footnotetext{
* Correspondence: azmina.hussain@duhs.edu.pk

'Dr. Ishrat-ul-Ibad Khan Institute of Oral Health Sciences, Dow University of Health Sciences, OJHA Campus, Suparco Road, Gulzar-e-Hijri, Scheme, Karachi 33, Pakistan

Full list of author information is available at the end of the article
} 


\section{Background}

Tobacco is amongst the leading evitable causes of global morbidity and mortality [1]. In contemporary times, nearly 6 million lives are lost due to tobacco consumption which is anticipated to rise exponentially and may hit 8 million by the year 2030 with its major burden in third world countries [2]. This will render tobacco as the major cause of deaths worldwide.

All various forms of tobacco have been associated with adverse health effects inclusive of oral cancer [3]. With 600 million people using betel quid (BQ) globally [4], and smokeless tobacco (SLT) use being more widely spread than ever [5]; the deadly combination is a constant uphill public health concern specially in South Asian countries in terms of increased morbidity and mortality from oral cancer [6].

Smokeless tobacco is the pre-dominant form of tobacco that is accountable for the most tobacco related ill health effects [7]. SLT contains nicotine and carcinogenic nitrosamines which cause more than a quarter million deaths mainly due to oral and pharyngeal cancers $[3,5]$.

Betel Quid (paan) with or without tobacco, areca nut (supari, chaalia), ghutka, niswar, tobacco smoking in all forms are established oral carcinogens by IARC $[6,8-10]$ which also cause oral potentially malignant lesions [4].

SLT consumption is quite acceptable in South Asian countries as part of their cultural and social norms [11]. At a very young age, individuals start consuming it as these products are readily available and considered as sweets [12]. A variety of factors are included and the list is not exhaustive to family values, easy access, cheap in cost, as dental pain relieving medicine, no enforcement of legislation on its use; are responsible factors for SLT wide spread use $[13,14]$. The women and young individuals in India, Pakistan and Bangladesh refrain from smoking due to cultural and traditional beliefs but there is no such hesitation in SLT and/or BQ use; rather parents encourage their children to use it [15].

Young individuals consider it as a very popular and acceptable product, thus, subsequently become addicted to it [16] because of arecoline (nicotinic based alkaloid in areca nut) $[17,18]$ and nicotine in SLT [19]. Once adolescents start consuming SLT, it becomes an essential component of their lives since SLT is the fourth commonly abused substances worldwide and develops dependency like alcohol, nicotine \& caffeine with both stimulating and relaxing effects [20-22]. School going children also get fascinated by the undesirable marketing of sparkling packages of SLT products and spend the substantial amount of their pocket money on the purchase of these dangerous substances $[23,24]$.

A majority of the users get engaged in this habit even before 15 years of age due to influence by the media
(40.2\%), family and friends' pressure (30.8\%) [25] while in another study, peer pressure (76\%) was reported.

Thus, the current survey is to establish the prevalence of smokeless tobacco and/or betel quid in school going adolescents, along with the combined effects of individual, social and environmental factors that influence the use of SLT and/or BQ in them. Previous studies have shown effects of either more individual based influencing factors on SLT and/or BQ use, and have not focused on adolescents $[5,26]$ or have taken tobacco use in smoked and/or both smoked alongside smokeless forms [27, 28]. This study is one of its kind in the current setting as no such large primary study has focused on the most vulnerable high-risk group for specific SLT and/or BQ use along with the determination of house-level, social, school-level and environmental factors that may influence their use.

\section{Methods}

Aim

Our purpose of the study was to observe the differential individual, social and environmental features amongst smokeless tobacco and/or Betel quid (SLT and/or BQ) users to determine the key influencers of its use in school going adolescents of Karachi.

\section{Data source}

This study was conducted at government and private schools of Karachi. With a population of approximately 24 million, Karachi is the largest city of Pakistan [29]. Karachi City government has divided the city into six (6) districts in 2013 with each district being further divided into administrative towns of total 18 in number [30].

\section{Sampling and study participants}

Out of six districts, 26 clusters (secondary schools) were selected by systematic random sampling which was proportionate to the number of each school type (ensuring equal participation of government and private schools). The students of 11-16 years of age, studying in grade VI Grade $\mathrm{X}$ were recruited by systematic sampling-kth number. Fifty-100 students per school were included in the study depending on the school and class size from each of the secondary classes that were present on the day of our visit till a desired number was reached.

This therefore resulted in a total sample size of 2200 that may be considered representative of the $11-16$ years adolescents of Karachi.

Students of younger or older than 11-16 years, and those who already were undergoing treatments for Oral Cancer were excluded.

\section{Survey participants}

For recruitment purposes, we contacted principals of selected schools (both government and private) to provide 
them with details regarding the purpose of the study and requested for their inclination to participate in the study. If any selected school refused to participate then another school of same profile was sent an invitation. Schools' heads were also requested to send consent forms (provided to schools) to the parents along with a covering letter in which they were provided with all relevant details regarding the study and were encouraged to contact principal investigator via a text on given contact number who then called parents to respond to all queries since we did not have toll-free numbers [31]. Parents were requested to sign an acceptance or refusal on the form and sent it back to school by a specific decided date.

\section{Data collection tool and study variables}

We used structured, pre-tested questionnaire (in which few were adapted from GYTS (Global Youth Tobacco Survey) [32]) that gathers the information pertinent to:

Individual based inquiry that included information regarding age, sex, parents' education and occupation, weekly pocket money (this was inquired as, "during an average week, how much money [PKR \{USD\}] do you have that you can spend on yourself, however you want?" a. 100-200 \{0.95-1.90 USD $\}$, b. 201-300 \{1.91-2.85 USD $\}$, c. 301-400 \{2.86-3.80 USD $\}$, d. 401-500\{3.81-4.74 USD $\}$ or e. more than $500\{4.74$ USD $\})$, and the school type (government or private schools).

Social/home based assessment that was inclusive of peers' and parents' SLT and/or BQ use, teachers' SLT and/ or BQ use status, and SLT and/or BQ use susceptibility if any close friend offers it (this was asked as, "if one of your best friends offered you smokeless tobacco and/or BQ, would you use it?" a. Definitely not. b. Probably not, c. Probably yes, d. Definitely yes).

School and environment level questions included availability of SLT and/or BQ at school canteen (the question was, "do you get to buy chewing tobacco, pan, chalia, naswar and gutka in school canteen?" a. Yes, b. No) and with outside hawkers (this was asked as, "do you get to buy chewing tobacco, pan, chalia, naswar and gutka from outside school hawkers?" a. Yes, b. No) and education imparted regarding harmful health effects of SLT and/or BQ use in classroom setting.

Outcome variable was current smokeless tobacco (SLT) and/or betel quid (BQ) use status where user was defined by the use of any or all type of SLT and/or BQ at least once in past 30 days [33] and non-user had not used any or all type of SLT and/or BQ once at least in past 30 days. The students were asked about their BQ and/or SLT consumption by asking:

Do you use any of the following products?

a. Paan (betel quid), b. Paan masala (chalia.betel nut), c. Zarda, d. Ghutka, e. Naswar or f. Others , please specify.
This was further re-assessed by second series of questions to avoid recall bias like,

1. How many numbers of chews per day you do?

2. Since how many years you have been chewing?

3. What type of SLT/or BQ you chew?

a. Areca nut alone, b. Betel quid without tobacco, c. Betel quid with tobacco, d. Any other type of SLT.

Based on the local school grading hierarchy, mostly less than 12 years old students were housed in lower secondary segment of the school while the older group comprised of higher secondary school stratum.

\section{Statistical analysis}

Data of the current study were analyzed by using Stata v14. Descriptive statistics including mean, frequency and percentages were reported, and Chi-square analysis was performed to determine significance of association between variables and outcome. Associations between the outcome variable "SLT and/or BQ use" and all study variables were assessed by using univariate and multivariate binary logistic regression analyses. Results were reported as both crude form and adjusted odds ratio after adjusting for all remaining individual, social and environmental level variables with 95\% confidence level. A $p$-value of <.05 was considered significant for all analyses.

\section{Results}

Overall, 2200 students participated from combined 13 government and 13 private schools of Karachi in this study. School's response rate was $80 \%$.

Sixty participants' information was incomplete/missing out of total 2200. The final analysis was based on 2140 participants' complete responses.

\section{Individual, social and environmental characteristics of adolescents associated with the SLT and/or BQ use Individual based characteristics}

An overall 30 days prevalence of SLT and/or BQ use was estimated to be $42.6 \%(n=912)$ of the total sample whereas $57.4 \%(n=1228)$ participants did not use it in past 30 days. Amongst users, 30.2\% $(n=275)$ aged less than or equal to 12 years while $637(69.8 \%)$ were more than 12 years of age; similar age profiling was evident for non-users. Age was positively associated with the SLT and/or BQ use. Approximately equal proportions of males and females comprised of non-user group while SLT and/ or BQ consumer group had more males than females which was significantly associated with the use $\left(x^{2}=\right.$ $16.12, \mathrm{df}=1, p$-value $<0.001)$. Both parents' education showed a positive relationship with the consumption of SLT and/or BQ. Most of the respondents got 100-300 
PKR (0.95-2.85 USD) as weekly pocket money which was pivotal in SLT and/or BQ chew. A significantly high proportion of users was found in co-education schools irrespective of them being government or private (Table 1 ).

Univariate analysis suggested that being a male, government school student, having weekly pocket money more than PKR 300 (2.85 USD) and studying in co-education system were significantly and positively associated with SLT and/or BQ use (Table 3).
Effect sizes (positive association with SLT and/or BQ use) of co-education or only boys' school adolescents, government school students and children who had a weekly pocket money that they had a luxury of spending the way they want, increased after multivariate adjustments (Table 3).

\section{Social characteristics}

The use of ST and/or BQ by adolescents was positively linked with its use by their peers $(\mathrm{x} 2=2.29, \mathrm{df}=3, p$ -

Table 1 Sociodemographic Characteristics of Adolescents regarding SLT and/or BQ Use $(n=2140)$

\begin{tabular}{|c|c|c|c|c|}
\hline & NON-USERS & USERS & chi-square value & $p$-value \\
\hline Characteristics & $N(\%)$ & $N(\%)$ & & \\
\hline \multicolumn{5}{|l|}{ Individual characteristics } \\
\hline \multicolumn{5}{|l|}{ Age } \\
\hline $11-12$ Years & $446(36.3 \%)$ & $275(30.2 \%)$ & 8.91 & 0.002 \\
\hline$>12$ Years & $782(63.7 \%)$ & $637(69.8 \%)$ & & \\
\hline \multicolumn{5}{|l|}{ Gender } \\
\hline Female & $549(44.7 \%)$ & $329(36.1 \%)$ & 16.12 & $<0.001$ \\
\hline Male & $679(55.3 \%)$ & $583(63.9 \%)$ & & \\
\hline \multicolumn{5}{|l|}{ School } \\
\hline Private & $833(67.8 \%)$ & $520(57.0 \%)$ & 26.33 & $<0.001$ \\
\hline Government & $395(32.2 \%)$ & $392(43.0 \%)$ & & \\
\hline \multicolumn{5}{|l|}{ Father's Education } \\
\hline No formal education & $331(27.0 \%)$ & $264(28.9 \%)$ & 34.39 & $<0.001$ \\
\hline Primary & $165(13.4 \%)$ & $182(20.0 \%)$ & & \\
\hline Secondary & $422(34.4 \%)$ & $318(34.9 \%)$ & & \\
\hline Higher Education & $310(25.2 \%)$ & $148(16.2 \%)$ & & \\
\hline \multicolumn{5}{|l|}{ Mother's Education } \\
\hline No formal education & $419(34.1 \%)$ & $363(39.8 \%)$ & 24.35 & $<0.001$ \\
\hline Primary & $197(16.0 \%)$ & $173(19.0 \%)$ & & \\
\hline Secondary & $408(33.2 \%)$ & $284(31.1 \%)$ & & \\
\hline Higher Education & $204(16.6 \%)$ & $92(10.1 \%)$ & & \\
\hline \multicolumn{5}{|l|}{ Parent's Occupation } \\
\hline Neither works & $61(5.0 \%)$ & $49(5.4 \%)$ & 0.56 & 0.907 \\
\hline Only father works & 967 (78.7\%) & $710(77.9 \%)$ & & \\
\hline Only mother works & $45(3.7 \%)$ & $31(3.4 \%)$ & & \\
\hline Both work & $155(12.6 \%)$ & $122(13.4 \%)$ & & \\
\hline \multicolumn{5}{|l|}{ Weekly pocket money } \\
\hline$<100$ & $130(10.6 \%)$ & $68(7.5 \%)$ & 17.18 & $<0.001$ \\
\hline $100-300$ & $727(59.2 \%)$ & $618(67.8 \%)$ & & \\
\hline$>300$ & $371(30.2 \%)$ & $226(24.8 \%)$ & & \\
\hline \multicolumn{5}{|c|}{ School Type-Gender Based } \\
\hline Only Girls & $258(21.0 \%)$ & $132(14.5 \%)$ & 20.38 & $<0.001$ \\
\hline Co-education & $644(52.4 \%)$ & $558(61.2 \%)$ & & \\
\hline Only Boys & $326(26.5 \%)$ & $222(24.3 \%)$ & & \\
\hline
\end{tabular}

SLT Smokeless tobacco, BQ Betel quid 
value $<0.001)$ and parents $\left(\chi^{2}=64.73, \mathrm{df}=2, p\right.$-value $<0.001$ ) (Table 2).

Univariate analysis indicated that adolescents whose peers used SLT and/or BQ had 6.8 times higher odds of consuming it as compared with those who did not have user peers (Table 3) and this remained significant after adjusting for SLT and/or BQ use by parents, teachers, use susceptibility, individual and environmental characteristics in a multivariate model though its effect size reduced $(\mathrm{OR}=2.68,95 \%$ CI 1.71-4.19, $p$-value <0.001) (Table 3). Either of the parents' use of SLT and/or BQ also encouraged use in adolescents as indicated by both univariate and multivariate analyses (Table 3).
The teenagers who will accept the offer of using this product by their friends, were 9 times more likely to use it as compared with those who would not accept it, though this association attenuated but remained statistically significant after adjusting for multiple covariates $(\mathrm{OR}=4.47,95 \%$ CI 3.10-6.44, $p$-value <0.001) (Table 3).

\section{Environmental characteristics}

Adolescents who did not have knowledge regarding harmful health effects of SLT and/or BQ were significant users of SLT and/or BQ $(\mathrm{X} 2=15.04, \mathrm{df}=2, p$-value $0.001)$ than those who attended awareness sessions (Table 2). Multivariate analysis indicated that there are

Table 2 Social \& Environmental Characteristics of Adolescents regarding SLT and/or BQ Use $(n=2140)$

\begin{tabular}{|c|c|c|c|c|}
\hline & NON-USERS & USERS & chi-square value & $p$-value \\
\hline Characteristics & $N(\%)$ & $N(\%)$ & & \\
\hline \multicolumn{5}{|l|}{ Social Characteristics } \\
\hline \multicolumn{5}{|l|}{ SLT and/or BQ use by peers } \\
\hline None of them uses it & $631(51.4 \%)$ & $201(22.0 \%)$ & 2.29 & $<0.001$ \\
\hline Some of them use it & $411(33.5 \%)$ & $370(40.6 \%)$ & & \\
\hline Most of them use it & $137(11.2 \%)$ & $235(25.8 \%)$ & & \\
\hline All of them use it & $49(4.0 \%)$ & $106(11.6 \%)$ & & \\
\hline \multicolumn{5}{|c|}{ SLT and/or BQ use by teachers } \\
\hline None of them uses it & $852(69.4 \%)$ & $606(66.4 \%)$ & 4.87 & 0.182 \\
\hline Some of them use it & $278(22.6 \%)$ & $236(25.9 \%)$ & & \\
\hline Most of them use it & $97(7.9 \%)$ & $67(7.3 \%)$ & & \\
\hline All of them use it & $1(0.1 \%)$ & $3(0.3 \%)$ & & \\
\hline \multicolumn{5}{|c|}{ SLT and/or BQ use by parents } \\
\hline No one uses it & $980(79.8 \%)$ & $586(64.3 \%)$ & 64.728 & $<0.001$ \\
\hline any one of them uses it & $226(18.4 \%)$ & $293(32.1 \%)$ & & \\
\hline Both of them use it & $22(1.8 \%)$ & $33(3.6 \%)$ & & \\
\hline \multicolumn{5}{|c|}{ Use susceptibility if closest friend offers it } \\
\hline Definitely Not & $997(81.2 \%)$ & $465(51.0 \%)$ & 2.93 & $<0.001$ \\
\hline Probably No & $127(10.3 \%)$ & $98(10.7 \%)$ & & \\
\hline Probably Yes & $53(4.3 \%)$ & $133(14.6 \%)$ & & \\
\hline Definitely Yes & $51(4.2 \%)$ & $216(23.7 \%)$ & & \\
\hline \multicolumn{5}{|l|}{ Environmental Characteristics } \\
\hline \multicolumn{5}{|c|}{ Class discussion in past 12 months regarding SLT and/or BQ use } \\
\hline Yes & $612(49.8 \%)$ & $378(41.4 \%)$ & 15.04 & 0.001 \\
\hline No & $597(48.6 \%)$ & $520(57.0 \%)$ & & \\
\hline Not sure & $19(1.5 \%)$ & $14(1.5 \%)$ & & \\
\hline \multicolumn{5}{|c|}{ SLT and/or BQ available at school canteen } \\
\hline No & $1121(91.3 \%)$ & $686(75.2 \%)$ & & \\
\hline Yes & $107(8.7 \%)$ & $226(24.8 \%)$ & 1.03 & $<0.001$ \\
\hline \multicolumn{5}{|c|}{ SLT and/or BQ available outside school } \\
\hline No & $1084(88.3 \%)$ & 508 (55.7\%) & & \\
\hline Yes & 144(11.7\%) & 404 (44.3\%) & 2.92 & $<0.001$ \\
\hline
\end{tabular}

SLT Smokeless tobacco, BQ Betel quid 
Table 3 Sociodemographic, Social \& Environmental Characteristics of Adolescents associated with SLT and/or BQ Use $(n=2140)$

\begin{tabular}{|c|c|c|c|c|}
\hline & OR $(95 \% \mathrm{Cl})$ & $p$-value & $\mathrm{aOR}(95 \% \mathrm{Cl})$ & $p$-value \\
\hline \multicolumn{5}{|l|}{ Characteristics } \\
\hline \multicolumn{5}{|l|}{ Individual characteristics } \\
\hline \multicolumn{5}{|l|}{ Age } \\
\hline $11-12$ Years & 1 & & 1 & \\
\hline$>12$ Years & $1.32(1.10-1.58)$ & 0.003 & $1.00(0.80-1.25)$ & 0.991 \\
\hline \multicolumn{5}{|l|}{ Gender } \\
\hline Female & 1 & & 1 & \\
\hline Male & $1.43(1.20-1.70)$ & $<0.001$ & $1.38(1.05-1.83)$ & 0.020 \\
\hline \multicolumn{5}{|l|}{ School } \\
\hline Private & 1 & & 1 & \\
\hline Government & $1.59(1.33-1.89)$ & $<0.001$ & $2.06(1.49-2.85)$ & $<0.001$ \\
\hline \multicolumn{5}{|l|}{ Father's Education } \\
\hline No formal education & 1 & & 1 & \\
\hline Primary & $1.38(1.06-1.80)$ & 0.017 & $0.96(0.68-1.36)$ & 0.860 \\
\hline Secondary & $0.94(0.76-1.17)$ & 0.609 & $0.86(0.65-1.14)$ & 0.314 \\
\hline Higher Education & $0.59(0.46-0.77)$ & $<0.001$ & $0.96(0.68-1.34)$ & 0.816 \\
\hline \multicolumn{5}{|l|}{ Mother's Education } \\
\hline No formal education & 1 & & 1 & \\
\hline Primary & $1.01(0.79-1.29)$ & 0.915 & $1.01(0.73-1.39)$ & 0.927 \\
\hline Secondary & $0.80(0.65-0.98)$ & 0.038 & $0.93(0.71-1.22)$ & 0.614 \\
\hline Higher Education & $0.52(0.39-0.69)$ & $<0.001$ & $0.89(0.61-1.30)$ & 0.897 \\
\hline \multicolumn{5}{|l|}{ Parent's Occupation } \\
\hline Neither works & 1 & & 1 & \\
\hline Only father works & $1.02(0.65-1.59)$ & 0.929 & $1.15(0.72-1.84)$ & 0.540 \\
\hline Only mother works & $0.93(0.72-1.20)$ & 0.595 & $1.22(0.61-2.43)$ & 0.572 \\
\hline Both work & $0.87(0.52-1.46)$ & 0.612 & $1.33(0.78-2.26)$ & 0.291 \\
\hline \multicolumn{5}{|l|}{ Weekly pocket money } \\
\hline$<100$ & 1 & & 1 & \\
\hline $100-300$ & $0.85(0.61-1.20)$ & 0.375 & $1.51(1.03-2.22)$ & 0.032 \\
\hline$>300$ & $1.39(1.14-1.70)$ & 0.001 & $1.17(0.77-1.79)$ & 0.445 \\
\hline \multicolumn{5}{|l|}{ School Type-Gender Based } \\
\hline Only Girls & 1 & & 1 & \\
\hline Co-education & $1.69(1.34-2.15)$ & $<0.001$ & $2.88(1.89-4.40)$ & $<0.001$ \\
\hline Only Boys & $1.33(1.01-1.74)$ & 0.038 & $2.00(1.27-3.14)$ & 0.003 \\
\hline
\end{tabular}

Social Characteristics

SLT and/or BQ use by peers

None of them uses it

1

Some of them use it

$2.82(2.28-3.49)$

$<0.001$

$<0.001$

Most of them use it

$5.38(4.13-7.01)$

$<0.001$

$<0.001$

All of them use it

$6.79(4.67-9.87)$

$<0.001$

$<0.001$

SLT and/or BQ use by teachers

None of them uses it

1

some of them use it

$1.19(0.97-1.46)$

0.807

$2.07(1.63-2.63)$

$3.02(2.23-4.09)$

$2.68(1.71-4.19)$

1

$1.18(0.93-1.51) \quad 0.157$ 
Table 3 Sociodemographic, Social \& Environmental Characteristics of Adolescents associated with SLT and/or BQ Use $(n=2140)$ (Continued)

\begin{tabular}{|c|c|c|c|c|}
\hline \multicolumn{5}{|l|}{ SLT and/or BQ Users } \\
\hline & OR $(95 \% \mathrm{Cl})$ & $p$-value & $\mathrm{aOR}(95 \% \mathrm{Cl})$ & $p$-value \\
\hline Most of them use it & $0.97(0.69-1.34)$ & 0.861 & $0.91(0.61-1.36)$ & 0.676 \\
\hline All of them use it & $4.21(0.43-40.64)$ & 0.213 & $1.29(0.11-14.64)$ & 0.833 \\
\hline \multicolumn{5}{|c|}{ SLT and/or BQ use by parents } \\
\hline No one uses it & 1 & & 1 & \\
\hline any one of them uses it & $2.16(1.73-2.65)$ & $<0.001$ & $1.52(1.19-1.94)$ & 0.001 \\
\hline Both of them use it & $2.50(1.44-4.34)$ & 0.001 & $1.42(0.71-2.82)$ & 0.314 \\
\hline \multicolumn{5}{|c|}{ Use susceptibility if closest friend offers it } \\
\hline Definitely Not & 1 & & 1 & \\
\hline Probably No & $1.65(1.24-2.20)$ & 0.001 & $1.36(0.98-1.89)$ & 0.059 \\
\hline Probably Yes & $5.38(3.84-7.53)$ & $<0.001$ & $3.36(2.30-4.90)$ & $<0.001$ \\
\hline Definitely Yes & $9.08(6.56-12.56)$ & $<0.001$ & $4.47(3.10-6.44)$ & $<0.001$ \\
\hline \multicolumn{5}{|l|}{ Environmental Characteristics } \\
\hline \multicolumn{5}{|c|}{$\begin{array}{l}\text { Class discussion in past } 12 \text { months } \\
\text { regarding SLT and/or BQ use }\end{array}$} \\
\hline Yes & 1 & & 1 & \\
\hline No & $1.41(1.18-1.67)$ & $<0.001$ & $1.25(1.01-1.55)$ & 0.033 \\
\hline Not sure & $1.19(0.59-2.40)$ & 0.622 & $1.09(0.47-2.50)$ & 0.831 \\
\hline \multicolumn{5}{|c|}{ SLT and/or BQ available at school canteen } \\
\hline No & 1 & & 1 & \\
\hline Yes & $3.45(2.69-4.42)$ & $<0.001$ & $1.29(0.94-1.76)$ & 0.107 \\
\hline \multicolumn{5}{|c|}{ SLT and/or BQ available outside school } \\
\hline No & 1 & & 1 & \\
\hline Yes & $5.98(4.81-7.44)$ & $<0.001$ & $3.65(2.82-4.73)$ & $<0.001$ \\
\hline
\end{tabular}

SLT Smokeless tobacco, $B Q$ Betel quid, $O R$ Odds ratio, $a O R$ adjusted odds ratio, $C l$ Confidence intervals, Significant results are italicized.

$25 \%$ more chances of SLT and/or BQ use if little or no awareness was created in class sessions (Table 3).

Availability of SLT and/or BQ at school canteen and with outside school hawkers $\left(\chi^{2}=2.92, \mathrm{df}=1, p\right.$-value 0.001 ) played a sizeable role in the use (Table 2 ). The users were 6 times more likely to use SLT and/or BQ if it was available with outside school hawker relative to when it was not accessible with outside school vendors, this was persistently indicated by both univariate $(\mathrm{OR}=$ 5.98, 95\% CI 4.81-7.44, $p$-value <0.001) and multivariate analyses $(\mathrm{OR}=3.65,95 \% \mathrm{CI} 2.82-4.73, p$-value $<0.001)$ (Table 3) after adjusting for other environmental, individual and social determinants for SLT and/or BQ use.

\section{Discussion}

In this study, we found that male students studying either in co-education or boys school, schools where availability of these products was substantial with an easy access, adolescents having peers, friends and parents using these products, and if there was less or no awareness provided at school regarding ill-health effects of SLT and/or BQ; they all set a conducive environment for more provocative use of SLT and/or BQ consumption.

Overall, the prevalence of SLT and/or BQ in our study (42.6\%) was lower than that found in another study which also included smoking and alcohol consumption (72.5\%) [26]. We included only different types SLT and/or BQ as these are more pertinent determinants of oral potentially malignant lesions and oral cancer in South East Asia including Pakistan(10, 15). Moreover, the products we included are more culturally acceptable and easily accessible to this high-risk adolescent group [1, 23, 34].

Our results based on individual factors prompting use, revealed that adolescents studying at government schools and male gender were more prone to the substance abuse as seen in other studies as well [34-37]. The use of SLT and/or BQ by males was a more prominent finding in contrast to the conclusion of South Asian betel-quid consortium where females were profound users as they were chronic users with low educational and awareness levels [38]. Whereas, in our present study we had adolescent 
females who had high awareness, were educated and were comparatively less chronic users.

Co-education schools have been shown to be a substantially significant contributing factor in the consumption of the SLT and/or BQ. This may be better understood if cultural backdrop is kept in forefront that by using these products, boys get more opportunity to impress girls since Pakistani cultural gives less or no freedom to interact and socialize with opposite gender as also seen in other cultures $[28,34,38]$. It is also a well-established fact that adolescents tend to use tobacco as a symbol of maturity and appeal which is provoked by the presence of the opposite gender $[34,39]$. Moreover, parents highly discourage their children interacting with opposite gender outside school hours probably due to the fear that kids may get distracted and get low scores in exams or may engage in sexual impropriety [40]. This could possibly explain the greater use of SLT and/or BQ among adolescents in the co-education system.

In our study, parents' higher education was evidently and inversely related to the probability of BQ/or SLT consumption as it can be anticipated and is also in agreement with other studies [27, 28],

Weekly pocket money which children could spend any way they wanted, proved to be an independent element of this product's use even after controlling for other confounders. This was not a very robust factor in our study as in other studies [28, 34, 41], despite of the rationale being mentioned elsewhere that these cheaper products are readily available as compared with other similar consumables.

Social factors like, peer pressure, use of the product by friend or either of the parents were the prevalent and significant contributors towards SLT and/or BQ use in our study. This finding along with 'curiosity to use' were major determinants in other studies that focused more on tobacco use and less on SLT and/or BQ thus augmenting the need of interventions aimed more towards these communal influences [34, 42-44]. Together with, susceptibility of indulging in SLT and/or BQ chew becomes highly substantial if any close friend offers it; this statistically significant finding of our study was coherent with other studies conducted elsewhere [27, 34, 44-47].

Our results suggested that knowledge regarding illeffects of substance abuse played a vital role in limiting the habit of all addictions including smoking, smokeless tobacco, alcohol consumption and areca nut consumption; this finding was in coherence with other studies $[38,48]$. If class awareness sessions regarding SLT and/ or BQ hazardous effects were not held in schools then there was $41 \%$ more likelihood of its consumption amongst users as compared with when they were frequent feature. Also, if these sessions are regularly held at schools, then there is a high probability to revert the "coolness" effect from use to non-use; where adolescents may refrain from its consumption in front of opposite gender to display maturity and maintain attractiveness.

Moreover, our study revealed that the easy availability of the product outside the school premises and sparklingly marketed products also play a significant role in the use as seen in other studies as well [25, 34].

Future interventions may be geared towards three major elements that can promise positive results in curbing the SLT and/or BQ use. Based on the results of the current study, these may include interventions focusing on awareness sessions on SLT and/or BQ harmful health effects, peer and friends pressure on use, and the products' availability outside schools. These results were inferred more robustly from this study as it was primarily aimed towards SLT and/or BQ unlike other studies that considered all forms of tobacco while SLT and/or BQ being just a small component of it [34, 42-44].

Limitations of the current study included firstly; as it is a self-reported data, it may have compromised the quality due to under reporting, though participation was completely voluntary with consent and participants were assured that anonymity of the information provided will be maintained. Secondly, as with all similar studies, bias in recall must be considered while interpreting data which was also regulated by prompting and asking questions in different ways to keep a counter check, for example, for outcome variable some students denied when they were asked about consumption of SLT and/or BQ but then in the next section, did describe the type of SLT and/or BQ used by them. Though the use was not validated with any hard outcome, yet it was ascertained by multiple questions. Thirdly, since it is a cross sectional study thus causality must be ascertained by other rigorous methods. Lastly, there may be un-known confounders that we did not control in our analysis.

Fortes of the current study can be emphasized by being first large representative sample based study to the best of our knowledge to assess risk behaviors in the form of combined effects of individual, social and environmental factors that promote/influence use of SLT and/or BQ in a high-risk group of school-going adolescents in Karachi. Approximately equal representation of both genders from both type of schools that is government and private, was again a highlighted feature of current study thus overall prevalence of use alongside, prevalence amongst each gender group was ascertained. Another accentuated feature of the contemporary study was getting information on most behaviors associated with SLT and/or BQ use amongst adolescents inclusive of all most probable individual, social and environmental contributors.

\section{Conclusion}

In summary, a co-education or boys' school male student, with influencers in the form of parents, friends and peers, 
lack of awareness regarding SLT and/or BQ undesirable ill-health effects, and availability of the cheap product with hawkers outside school; all contribute positively towards enhanced risk of substance abuse in adolescents. These associations were very strongly related with more use. School based interventions which focus on these contributors might bring out positive results in curbing the habit and as a result reducing the disease burden.

\section{Abbreviations}

BQ: Betel Quid; PKR: Pakistani currency; SLT: Smokeless Tobacco

\section{Acknowledgements}

Post Graduate trainee and undergraduate dental hygiene students are hereby acknowledged for their support in conducting school based survey.

\section{Funding}

Authors have no funding to report.

\section{Availability of data and materials}

The datasets generated and/or analyzed during the current study are not publicly available as not all authors and investigators have agreed, but are available from the corresponding author on reasonable request.

\section{Authors' contributions}

$\mathrm{KS}$ and $\mathrm{AH}$ conceived the idea of the work, $\mathrm{AH}$ sorted all approvals and collected the data, AH ran the analysis with statistical support from SZ, both $\mathrm{AH}$ and SZ interpreted the results, KS supervised throughout the project and in drafting of manuscript. All authors read and approved the final manuscript.

\section{Ethics approval and consent to participate}

The study was critically reviewed by scientific committee of Dow University of Health Sciences (DUHS), followed by which ethical parameters were scrutinized by team members of Institutional Review Board (IRB). After careful analysis, ethical permission was given by IRB-DUHS (Reference Number: IRB-725/DUHS/ Approval/2016/219). Consent was attained from all school principals and parents for children's participation.

\section{Consent for publication}

Not applicable.

\section{Competing interests}

The authors declare that they have no competing interests.

\section{Publisher's Note}

Springer Nature remains neutral with regard to jurisdictional claims in published maps and institutional affiliations.

\section{Author details}

'Dr. Ishrat-ul-Ibad Khan Institute of Oral Health Sciences, Dow University of Health Sciences, OJHA Campus, Suparco Road, Gulzar-e-Hijiri, Scheme, Karachi 33, Pakistan. ${ }^{2}$ School of Public Health, Dow University of Health Sciences, OJHA Campus, SUPARCO road, Gulzar e Hijiri, Karachi, Pakistan. ${ }^{3}$ Institute of Health and Wellbeing, Public Health, University of Glasgow, 1-Lilybank Gardens, G12 8RZ, Glasgow, UK.

Received: 14 July 2017 Accepted: 15 November 2017

Published online: 28 November 2017

\section{References}

1. Shrivastava N, Verma N, Bhawnani D, Soni G. Prevalence of smokeless tobacco use among school going adolescent students of Raipur city Chhattisgarh state, India. Int J Res in Med Sci. 2017;3(4):921-4.

2. Organization WH. WHO report on the global tobacco epidemic, 2011. Geneva: World Health Organization; 2016.

3. Wyss AB, Hashibe M, Lee YC, Chuang SC, Muscat J, Chen C, Schwartz SM, Smith E, Zhang ZF, Morgenstern H, Wei Q. Smokeless tobacco use and the risk of head and neck cancer: pooled analysis of US studies in the INHANCE consortium. Am J Epidemiol. 2016:1-4

4. Zaw K-K, Ohnmar M, Hlaing M-M, Win S-S, Aye P-P, Shwe S, et al. Betel quid and oral potentially malignant disorders in a periurban township in Myanmar. PLoS One. 2016;11(9):e0162081.

5. Sinha DN, Suliankatchi RA, Gupta PC, Thamarangsi T, Agarwal N, Parascandola M, Mehrotra R. Global burden of all-cause and cause-specific mortality due to smokeless tobacco use: systematic review and metaanalysis. Tob Control. 2016:tobaccocontrol-2016.

6. Chuang SL, Su WW, Chen SL, Yen AM, Wang CP, Fann JC, Chiu SY, Lee YC, Chiu HM, Chang DC, Jou YY. Population-based screening program for reducing oral cancer mortality in 2,334,299 Taiwanese cigarette smokers and/or betel quid chewers. Cancer. 2017:123(9):1597-609.

7. Gupta PC, Ray CS. Smokeless tobacco and health in India and South Asia. Respirology. 2003:8(4):419-31.

8. Lin C-F, Wang J-D, Chen P-H, Chang S-J, Yang Y-H, Ko Y-C. Predictors of betel quid chewing behavior and cessation patterns in Taiwan aborigines. BMC Public Health. 2006;6(1):1.

9. Madathil SA, Rousseau M-C, Wynant W, Schlecht NF, Netuveli G, Franco EL, et al. Nonlinear association between betel quid chewing and oral cancer: implications for prevention. Oral Oncol. 2016:60:25-31.

10. Humans IWGotEoCRt, Organization WH, Cancer IAfRo. Betel-quid and arecanut chewing and some areca-nut-derived nitrosamines: IARC; 2004.

11. Anwar S, Williams SA, Scott-Smith J, Sage H, Baweja S, Singal M, et al. A comparison of attitudes and practices of gutka users and non-users in Chitrakoot, India. Prim Dent Care. 2005;12(1):5-10.

12. Sorensen G, Gupta PC, Sinha DN, Shastri S, Kamat M, Pednekar MS, et al. Teacher tobacco use and tobacco use prevention in two regions in India: qualitative research findings. Prev Med. 2005;41(2):424-32.

13. Croucher R, Pau AK, Jerreat M, Begum S, Marcenes W. Oral health of Bangladeshi women tobacco-with-paan users and self-reported oral pain following tobacco cessation. J Public Health Dent. 2003;63(4):235-9.

14. Kakde $S$, Bhopal R, Jones C. A systematic review on the social context of smokeless tobacco use in the south Asian population: implications for public health. Public Health. 2012;126(8):635-45.

15. Hossain MS, Kypri K, Rahman B, Milton AH. Smokeless tobacco consumption in the south Asian population of Sydney, Australia: prevalence, correlates and availability. Drug Alcohol Rev. 2014;33(1):86-92.

16. Mishra S, Mishra M. Tobacco: its historical, cultural, oral, and periodontal health association. J Int Soc Prev Community Dent. 2013;3(1):12.

17. Ho YC, Yang SF, Lee SS, Chang YC. Regulation of hypoxia-inducible factor1a in human buccal mucosal fibroblasts stimulated with arecoline. J Formos Med Assoc. 2017;116(6):484-7.

18. Meyerhof W. Articles highlighted. Chem Senses. 2016:41(1):1.

19. Khaja AH, Zwiad AA, Tarakji B, Gazal G, Albaba F, Kalajl N, et al. The dependence on smokeless tobacco in the south Asian communities in East London. Glob J Health Sci. 2016;8(1):194.

20. Winstock A. Areca nut-abuse liability, dependence and public health. Addict Biol. 2002; $7(1): 133-8$

21. Boucher BJ, Mannan N. Metabolic effects of the consumption of Areca Catechu. Addict Biol. 2002;7(1):103-10.

22. Warnakulasuriya $S$, Peters T. Introduction: biology, medical and socioeconomic aspects of areca nut use. Addict Biol. 2002:7(1):75-6.

23. Williams S, Malik A, Chowdhury S, Chauhan S. Sociocultural aspects of areca nut use. Addict Biol. 2002;7(1):147-54

24. Shrivastava N, Verma N, Bhawnani D, Soni GP. Prevalence of smokeless tobacco use among school going adolescent students of Raipur city Chhattisgarh state, India. Int J Res Med Sci. 2015;3(4):921-4.

25. Ali NS, Khuwaja AK, Ali T, Hameed R. Smokeless tobacco use among adult patients who visited family practice clinics in Karachi, Pakistan. J Oral Pathol Med. 2009;38(5):416-21.

26. Nagpal R, Nagpal N, Mehendiratta M, Marya CM, Rekhi A. Usage of betel quid, areca nut, tobacco, alcohol and level of awareness towards their adverse effects on health in a north Indian rural population. Oral Health Dent Manag. 2014;13(1):81-6.

27. Bhaskar RK, Sah MN, Gaurav K, Bhaskar SC, Singh R, Yadav MK, et al. Prevalence and correlates of tobacco use among adolescents in the schools of Kalaiya, Nepal: a cross-sectional questionnaire based study. Tob Induc Dis. 2016;14(1):11.

28. Heo J, Oh J, Subramanian S, Kawachi I. Household and school-level influences on smoking behavior among Korean adolescents: a multilevel analysis. PLoS One. 2014;9(6):e98683. 
29. Valliani A, Ahmed B, Nanji K, Valliani S, Zulfiqar B, Fakih M, et al. Use of smoke-less tobacco amongst the staff of tertiary care hospitals in the largest City of Pakistan. Asian Pac J Cancer Prev. 2012;13(5):2315-7.

30. Ali TS, Mogren I, Krantz G. Intimate partner violence and mental health effects: a population-based study among married women in Karachi, Pakistan. Int J Behav Med. 2013;20(1):131-9.

31. Gansky SA, Ellison JA, Rudy D, Bergert N. Cluster-randomized controlled trial of an athletic trainer-directed spit (smokeless) tobacco intervention for collegiate baseball athletes: results after 1 year. J Athl Train. 2005;40(2):76.

32. Warren CW, Riley L, Asma S, Eriksen MP, Green L, Blanton C, et al. Tobacco use by youth: a surveillance report from the global youth tobacco survey project. Bull World Health Organ. 2000;78(7):868-76.

33. Nelson DE, Mowery P, Tomar S, Marcus S, Giovino G, Zhao L. Trends in smokeless tobacco use among adults and adolescents in the United States. Am J Public Health. 2006;96(5):897-905.

34. Narain R, Sardana S, Gupta S, Sehgal A. Age at initiation \& prevalence of tobacco use among school children in Noida, India: a cross-sectional questionnaire based survey. Indian J Med Res. 2011;133(3):300.

35. Pradhan PMS, Niraula SR, Ghimire A, Singh SB, Pokharel PK. Tobacco use and associated factors among adolescent students in Dharan, eastern Nepal: a cross-sectional questionnaire survey. BMJ Open. 2013;3(2):e002123.

36. Hussain HY, Satar BAA. Prevalence and determinants of tobacco use among Iraqi adolescents: Iraq GYTS 2012. Tob Induc Dis. 2013;11(1):14.

37. Vidhubala E, Sahaya G, Vijayalakshmi S, Bharathi P, Quarishy ZB. Prevalence of tobacco use among school children, exposure to passive smoking and their knowledge level about tobacco control in Chennai city, Tamil Nadu-A School Based Survey. Journal of Indian Association for Child \& Adolescent Mental Health. 2014;10(2).

38. Lee CH, AMS K, Warnakulasuriya S, Yin BL, Zain RB, Ibrahim SO, et al. Intercountry prevalences and practices of betel-quid use in south, southeast and eastern asia regions and associated oral preneoplastic disorders: an international collaborative study by asian betel-quid consortium of south and east Asia. Int J Cancer. 2011;129(7):1741-51.

39. Spijkerman R, van den Eijnden RJ, Engels RC. Self-comparison processes, prototypes, and smoking onset among early adolescents. Prev Med. 2005: 40(6):785-94.

40. Heo J, Oh J, Subramanian S, Kim Y, Kawachi I. Addictive internet use among Korean adolescents: a national survey. PLoS One. 2014;9(2):e87819.

41. Filippidis FT, Laverty AA, Gerovasili V, Vardavas Cl. Two-year trends and predictors of e-cigarette use in 27 European Union member states. Tob Control. 2017;26(1):98-104.

42. Danawala SA, Arora M, Stigler MH. Analysis of motivating factors for smokeless tobacco use in two Indian states. Asian Pac J Cancer Prev. 2014; 15(6):6553-8.

43. Arora M, Tewari A, Dhavan P, Nazar GP, Stigler MH, Juneja NS, et al. Discussions with adults and youth to inform the development of a community-based tobacco control programme. Health Educ Res. 2013, 28(1):58-71.

44. Kulkarni VP, Varma PP. Prevalence of tobacco smoking and impact of peer groups on smoking behavior among adolescent students.

45. Myint SK, Narksawat K, Sillabutra J. Prevalence and factors influencing betel nut chewing among adults in west insein township, yangon, myanmar. Southeast asian journal of tropical medicine and public. Health. 2016;47(5): 1089-97.

46. Tung T-H, Chiu Y-H, Chen L-S, Wu H-M, Boucher B, Chen T-H. A populationbased study of the association between areca nut chewing and type 2 diabetes mellitus in men (Keelung community-based integrated screening programme no. 2). Diabetologia. 2004;47(10):1776-81.

47. Chou C-Y, Cheng S-Y, Liu J-H, Cheng W-C, Kang I-M, Tseng Y-H, et al. Association between betel-nut chewing and chronic kidney disease in men. Public Health Nutr. 2009;12(05):723-7.

48. Lee C, Ko Y, Huang H, Chao Y, Tsai C, Shieh T, et al. The precancer risk of betel quid chewing, tobacco use and alcohol consumption in oral leukoplakia and oral submucous fibrosis in southern Taiwan. Br J Cancer. 2003:88(3):366-72.

\section{Submit your next manuscript to BioMed Central and we will help you at every step:}

- We accept pre-submission inquiries

- Our selector tool helps you to find the most relevant journal

- We provide round the clock customer support

- Convenient online submission

- Thorough peer review

- Inclusion in PubMed and all major indexing services

- Maximum visibility for your research

Submit your manuscript at www.biomedcentral.com/submit
Biomed Central 